\title{
Study of the Vision System's Impact on Increasing the Reliability of the Production System
}

\author{
Jakub Franek, Bartłomiej Nalepa \\ Silesian University of Technology, Poland
}

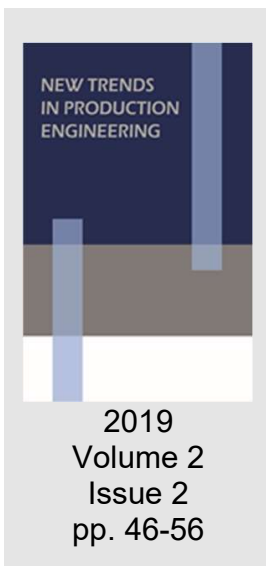

Date of submission to the Editor: 09/2019

Date of acceptance by the Editor: 11/2019

\section{INTRODUCTION TO PROBLEM, OPERATOR FAULTS AND THEIRS EFFECTS ON WORK OF PRODUCTION LINE}

In one production company there is a problem of often stops of the production line, because of operators' faults. The robot picks the products from the mould in injection moulding machine and takes them out for placing on the rotary magazine table next to the machine. Outside the safety fence, there is second, similar placing magazine, which must be unloaded manually by the operator during the robot performs the palletisation. After the completion of palletisation by the robot in safety area, the table must be turned by $180^{\circ}$. When the operator will not unload all products from the magazine and turn the table inside the safety area, the robot will not recognize the presence of some products in magazine and start palletisation from the first product. This will lead to collision between chuck plate and products left in the magazine. Of course, the collision will destroy the chucking plate by bending the metal plates or cutting the silicone suction cups. During the collision, torque on servomotor will exceed the allowed level and the robot will be stopped because of safety reasons. Before start-up of the whole production line, the chuck plate must be repaired, and some robot positions must be readjusted for proper work. The whole procedure takes a few hours in optimistic situation. If such a thing happens during night shift, it takes much longer, as there are no maintenance people with robot programming skills.

\section{DEFINING THE NEEDS}

A safety system must be implemented in current robot control system to prevent the collisions by operator fault described in paragraph 1 . The system must detect products left unloaded by the operator in magazine and don't allow to turn the table, predicting the stoppage of production line (Michalski, 2016). The table is hold in position by a locking pin on pneumatic cylinder (Michalski \& Hetmanczyk, 2015). After completion of palletisation, digital output signal from robot opens the pneumatic valve and the pin on pneumatic cylinder unlocks the table, allowing for its rotation. Digital output signal from robot must not be active, when 
the safety system detects any products left in the magazine. If such situation happens, the operator must unload all products first and then the locking pin will unlock the rotation possibility of the table. The robot will await completion of table's rotation in safe waiting position. The system has to proof the mistakes according to Poka-Yoke methodology (Hetmanczyk \& Michalski, 2013).

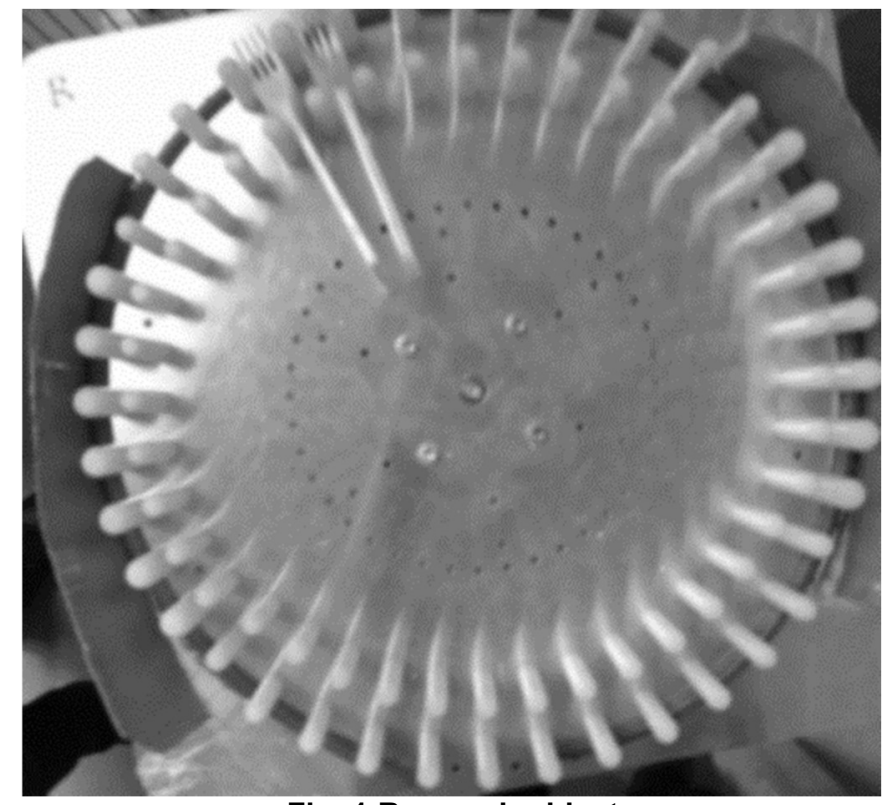

Fig. 1 Research object

Digital input signal must be delivered to the robot from some external sensor (Michalski \& Hetmanczyk, 2015), which will detect the products in the table outside the safety fence, so before the rotation of the table.

The system must be flexible enough to work with at least 5 different magazines, all have their individual placing pattern. Most of 5 magazines can have products with variable colours, mainly transparent, white and black.

Also, the system has to match the budget defined by managing staff of the company. The budget has been set to around 6.000-7.000 zlotys, with possibility to increase up to 10.000 zlotys basing on extra precise and easy to operate system.

\section{BRAINSTORMING, DEFINING THE POSSIBLE SOLUTIONS}

In order to develop a system described in previous paragraph, a brainstorm has been performed in order to define the possible solutions for the system. During a brainstorm, following detection systems have been listed out:

- Mechanical

- Ultrasonic

- Photo optic

- Reflective

- Laser

- Vision 2D

- Height measurement

- Vision 3D 


\section{FIRST EVALUATION OF ALL IDEAS, PROS AND CONS.}

After the brainstorm, first, theoretical evaluation of all ideas has been performed. The solutions were checked for ease of implementation, reliability, accuracy, costs, ease of use. Mechanical system was rejected because 5 different magazines doesn't have any common pattern, in which some mechanical sensor could check the lack of products. Photo optic, reflective and laser were rejected because of the same problem and what is more, up to 46 sensors would be necessary for one magazine. In this situation, we decided to check first the cheapest solution left - ultrasonic sensor, if it will not work, then to try with 2D camera and later with 3D height measuring camera.

\section{FIRST ATTEMPT - ULTRASONIC SENSOR SOLUTION}

The first attempt was made with ultrasonic sensor SICK UM30. Main advantage of this solution should be low cost and no difference between colour of the products (Sick AG, 2018). The sensor has been mounted $1030 \mathrm{~mm}$ above the magazine, in its central point.

The results were not satisfying. Although the sensor detected even small quantities of products, what was very good, it was able only to detect the products in the central area of magazine. When it has been mounted higher above magazine, to make the detection area bigger, the accuracy has dropped massively, thus making the detection not stable. Also, the magazines have many guiding pins or support elements for the products, all of them made some ultrasonic noises, lowering the detection accuracy significantly. After many attempts, the idea was abandoned, and we decided to try a 2D vision system.

\section{SECOND ATTEMPT - 2D VISION SYSTEM}

Next, the 2D vision camera PIM60 from SICK has been tested. This solution is much more expensive than ultrasonic sensor, but in theory, should provide much better accuracy and higher trust level to the output (Sick AG, 2017). The sensor was mounted in similar place as an ultrasonic sensor.

Unfortunately, the use of sensor was not so easy in production practice. Each product in each colour required his own, separate job declared for image processing application. In total there would be 13 jobs (5 products in different colours), but the camera had memory only for 9 tasks (Sick AG, 2018).

Changing the camera's tasks between themselves was quite problematic for maintenance staff during switch between produced elements as well. Also, 4 last jobs would have to be set manually, because of no memory left. However, the most crucial problem was the image repeatability. All magazines are made basing on precision aluminium plates, which are milled from both sides. This creates a very smooth surface, which also reflects light very well. The reflected light caused many interferences on camera image. What is worse, the conditions vary a lot during day and night, basing on daylight, flood lamps, etc. The angle and place of reflection was changing as well basing on light source (window, ceiling lamp). The environment could not be separated from light sources, because the easy handling access for operator must be ensured. Different types 
of filters were tested e.g. transparent, UV block, all combined with or without infrared light. After many days of tests, we abandoned this idea, as it was not accurate and safe enough. Probably only 3D vision system like Trispector from Sick will work with no complications and not depending on colours, what should make just 5 jobs to declare. However, the Trispector camera exceeded the budget significantly.

\section{HIRD ATTEMPT - 3D VISION SYSTEM}

As the 2D vision system was not accurate and easy to operate, we decided to go even more professional and use the 3D vision system 03D301 from IFM. The camera was even cheaper than PIM60 from SICK and should measure the height of elements on magazine (IFM electronic $\mathrm{GmbH}, 2018$ ). The camera has been mounted in the same position as PIM60, covering full magazine with its view range. The height of the elements is measured on infrared basis.

Our idea was to teach the height profile of the empty magazine and declare it as proper one. All abbreviations of this profile should be rejected and set false on the digital signal to robot's control unit. Unfortunately, the software delivered with camera has very little amount of options and possibilities. It even doesn't have any possibility to compare live image with reference image. Thus, not allowing to create jobs and deliver the digital output directly from camera to robot's programmable logic controller (IFM electronic $\mathrm{GmbH}, 2017$, IFM electronic $\mathrm{GmbH}$, 2018). Even though we decided to make a simulation.

After the initial setup we put some products in the magazine in the way, the operator will leave them forgotten. Unfortunately, again the light reflected in similar way as it was with PIM60. This made some area of magazine not seen, as the light reflection was so big. The products were little bit small to detect with this camera because of its image resolution. Also, the transparent products were not detected accurately, because of different light reflection coefficient.

In order to realize the measurement with a 3D camera, a measuring path was used as in Fig. 2.

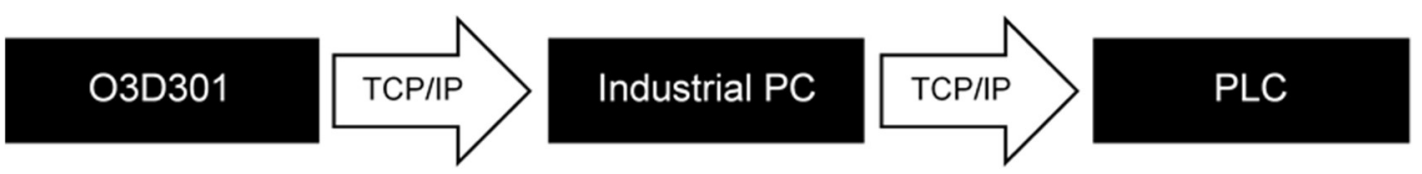

Fig. 2 Measuring path

The image was sent from the camera via the TCP/IP protocol to the industrial computer (Michalski, 2018) on which the image processing software was installed using the PMDSDK2 (PMDSDK2, 2019) and OpenCV (OpenCV, 2019) libraries. The algorithm analysed the image and then sent the data to the PLC using the TCP/IP protocol to see if all elements from the table have been removed.

Assuming that the image in the field of view of the camera will be repeatable except for the presence of the examined elements, a characteristic picture can be separated from the image. The image from the camera is shown in Figure 3. 


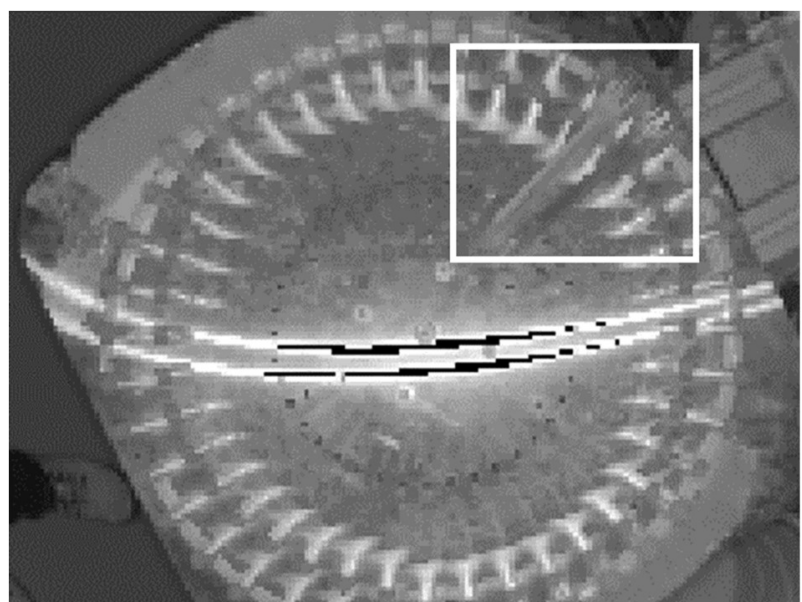

Fig. 3 Image from camera O3D301 (based on if Vision Assistant)

In Figure 3 there are elements left on the table marked with a frame. The analysis of the image shows that a circle describing the center of the table can be determined (Figure 4 - bigger white circle) and add a circle with a smaller radius (Figure 4 - smaller white circle). The result of the action is to obtain a ring containing characteristic elements (Figure 4 - black circle).

Circles marked in Fig. 4 can be presented along with parameters to define the circle equation (Figure 5).

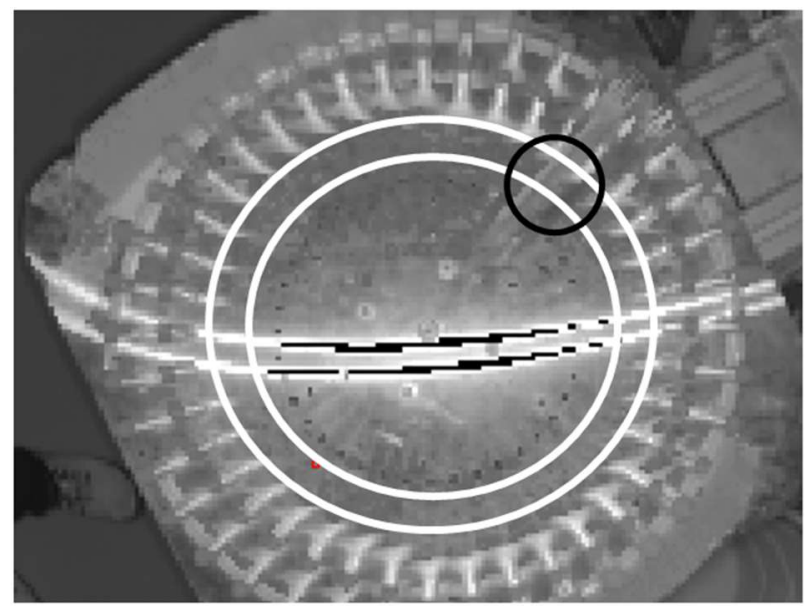

Fig. 4 Picture from O3D301 camera with a characteristic ring (based on if Vision Assistant)

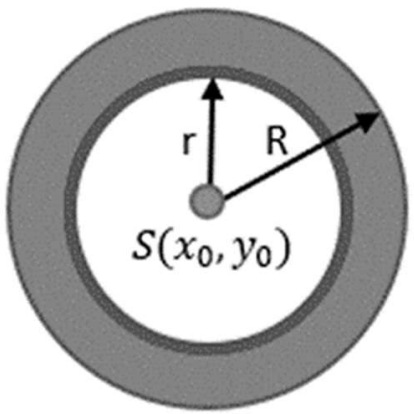

Fig. 5 Model of the cut ring 
The ring in Figure 5 can be described by the following circle equations (Ivanov \& Tabachinikov, 2019, Stevenhagen, 2019, Yoruk at al., 2006, Tan at al., 2010, Coetzee and Botha, 1993):

$$
\left\{\begin{array}{l}
\left(x-x_{0}\right)^{2}+\left(y-y_{0}\right)^{2}=R \\
\left(x-x_{0}\right)^{2}+\left(y-y_{0}\right)^{2}=r
\end{array}\right.
$$

On the basis of (1) you can determine the inequalities that the ring has to meet:

$$
\left\{\begin{array}{l}
\left(x-x_{0}\right)^{2}+\left(y-y_{0}\right)^{2} \leq R \\
\left(x-x_{0}\right)^{2}+\left(y-y_{0}\right)^{2} \geq r
\end{array}\right.
$$

The system of equations (2) can be presented in the form of an equation:

$$
r \leq \sqrt{\left(x-x_{0}\right)^{2}+\left(y-y_{0}\right)^{2}} \leq R
$$

The equation can be represented in the following form of the pseudocode:

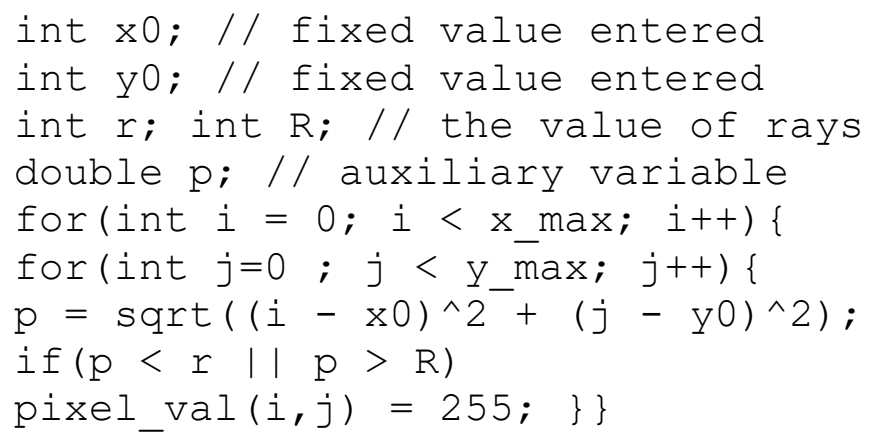

The effect of the algorithm is shown in Figure 6 (the characteristic area is marked). Additionally, in the operation of the algorithm, a tool was used to trim the object by determining a square based on the value of a larger radius. The procedure was aimed at reducing the number of calculations.

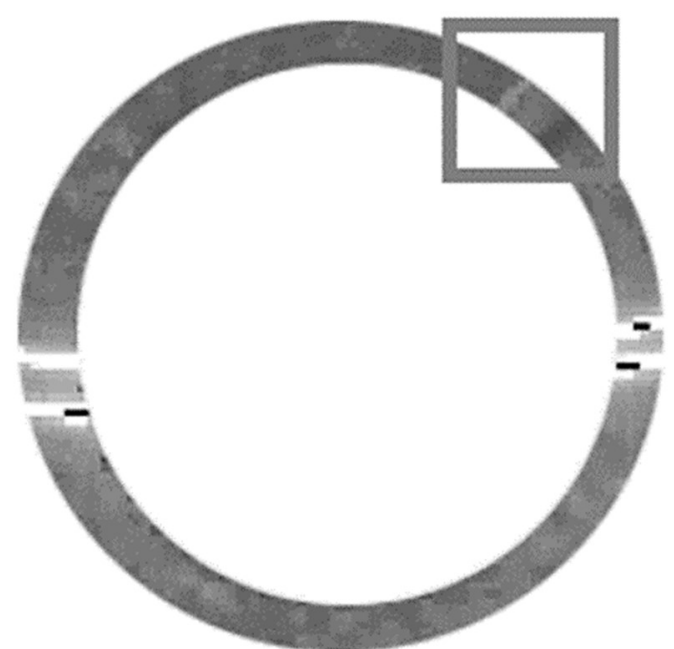

Fig. 6 Ring with characteristic elements

The fragment of the image from the 3D camera has been subjected to filtration (including the Kernel filter (He at al., 2017)). Then the Canna edge detection algorithm was introduced (Canny, 1986, Banas \& Nalepa, 2017), (Nalepa et al., 2018). The results of the algorithm are presented in Figure 7. 


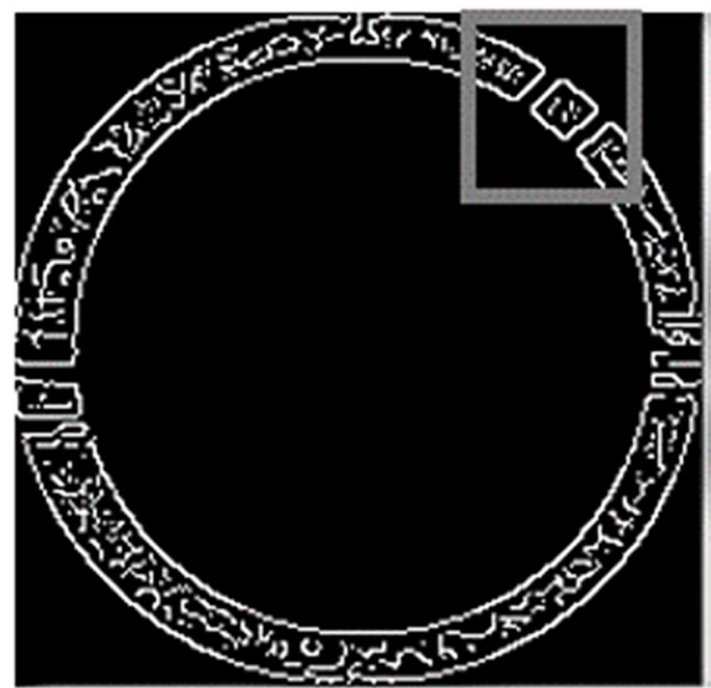

Fig. 7 The effect of filtration and edge detection algorithm to Fig. 6

Subsequently, an algorithm for contour detection was used for the result of the edge detection process. Depending on the number of detected contours (Lankton \& Tannenbaum, 2008), the algorithm sent information to the PLC whether a given object is on the table (Figure 8).

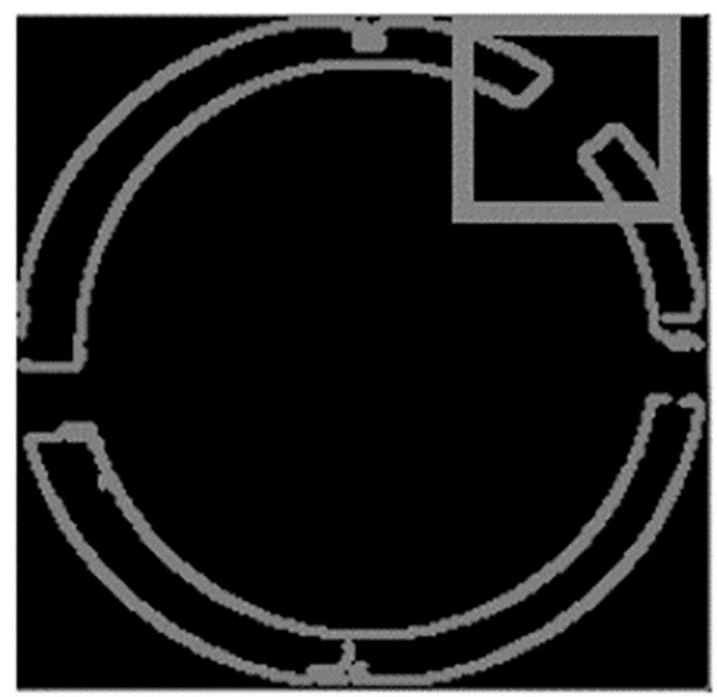

Fig. 8. The number of outlines determined

Testing the 3D camera directly does not allow to determine how many items on the table are left by the operator. In further analyses, a camera was used to return the image in the RGB colour palette. The downloaded image (Figure 9) was subjected to: the process of determining the characteristic ring (Figure 10), the algorithm of edge detection (Figure 11) and determining the number of contours (Figure 12). 


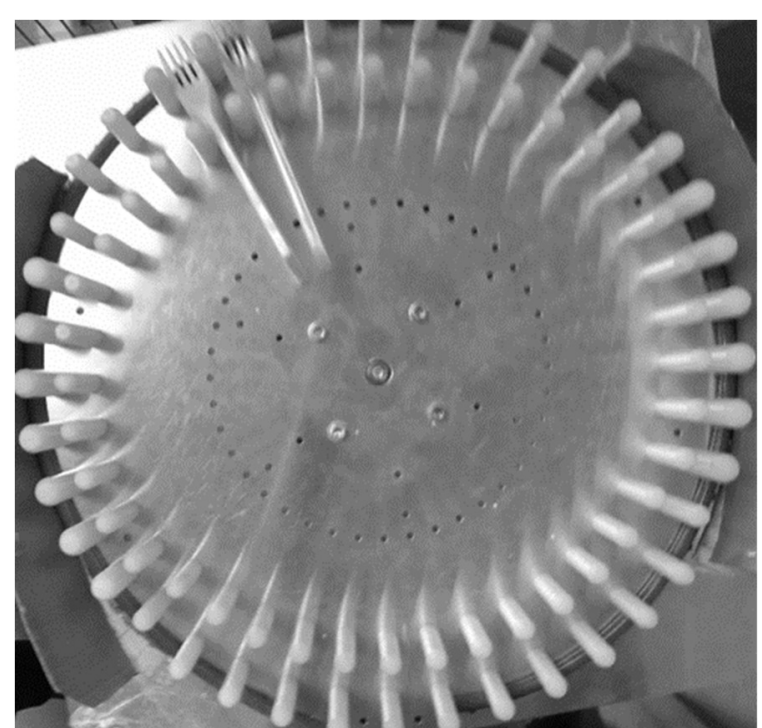

Fig. 9 RGB image of the table

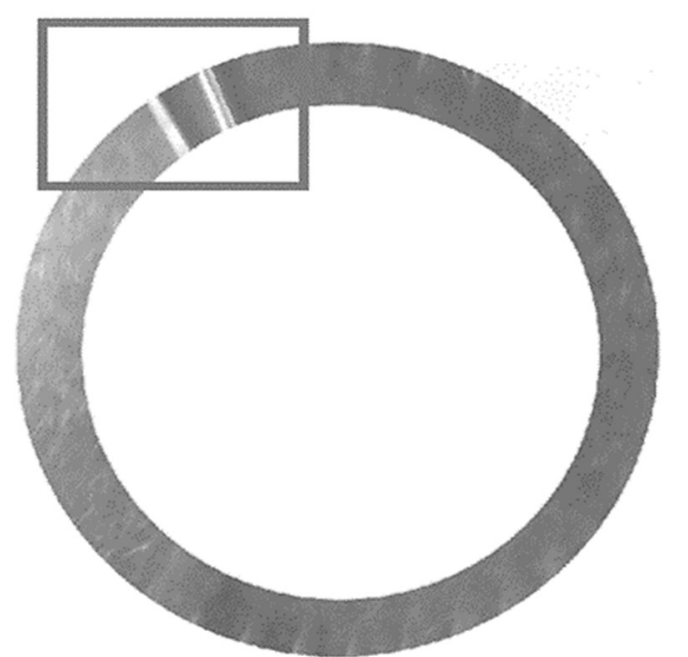

Fig. 10 Ring with characteristic elements - RGB image

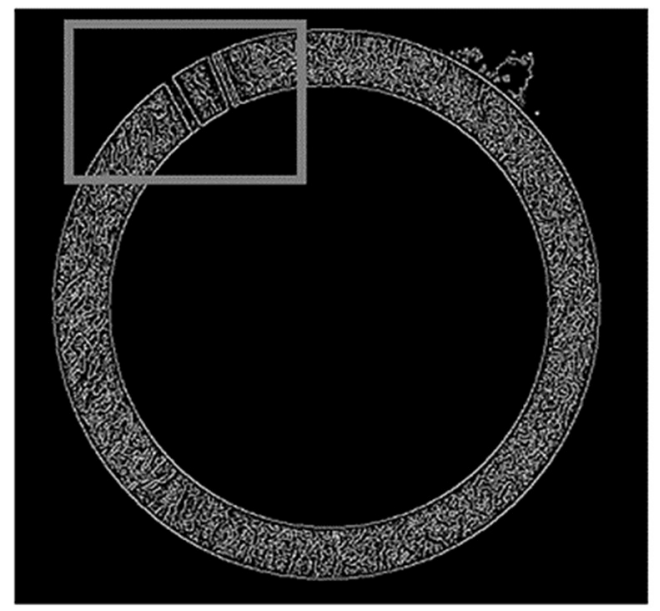

Fig. 11 The effect of applying the edge detection algorithm to Fig. 10

Analysis of the use of the 3D camera and the image returned in the RGB colour palette allow to state that the image from a standard 2D camera allows you to determine the number of elements left on the table by the operator. In addition, no filtration was used in the RGB camera. 


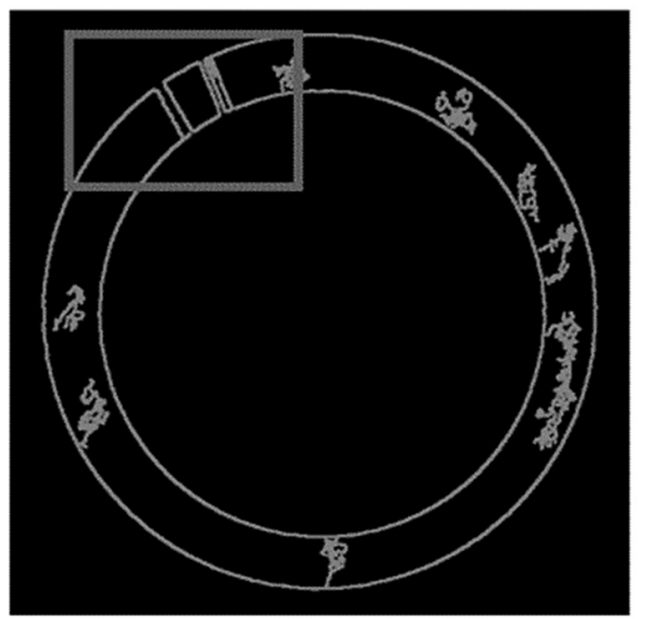

Fig. 12 Determined number of contours - RGB image

\section{VALIDATION OF SOLUTION}

The study compared the operation of two 3D and RGB cameras in the situation of detecting items left by the operator on the table, which can lead to a serious failure of the entire system. First, the image taken from the 3D camera was analysed. Due to the repetitive nature of the tests - the table will always be in the same position - the way of identifying the leftover elements was defined by defining the characteristic rings. The algorithm consists in cutting out a fragment of the centre of the table in the form of a ring with a similar value of both defining rays. Then the cut-out area is filtered and the edges appearing on the analysed section are determined. Subsequent contours and line length of each contour are determined, due to the elimination of contours with a low surface area disturbances. In the last stage of the algorithm's operation, the number of contours is determined and compared to the number of outlines of the reference image.

The next stage of the research was the use of a camera that returns the image in the RGB colour palette. In the case of this image, an analogous algorithm was used as for the 3D camera image, except for the lack of image filtering.

As a result of the research, it can be concluded that the image from the RGB camera allows for a more accurate image analysis in the presented industrial application. The returned image does not contain defective pixels and is less susceptible to factors that increase image distortion. The image in the RGB colour palette also allows to determine the number of elements left in the table segments. In addition, the RGB image was not subjected to filtration.

Unfortunately, the system is still not stable enough to implement it in production reality and requires adding one extra PLC and/or industrial PC in the system (Michalski, 2019). It can be stated, that more advanced image processing algorithms were necessary to obtain any better results compared to results made on software delivered with cameras. 


\section{REFERENCES}

Banas, W., Nalepa, B. (2017) Recognition of Text Commands and Control of the Mobile Robot Starter Kit 2.0. Mechatronics 2017 - Ideas for Industrial Applications, pp 1019.

Canny, J. (1986). A Computional Approach to Edge Detection. IEEE Transactions on Pattern Analysis and Macine Intelligence, Vol. 8, No. 6, 1986.

Coetzee, L., Botha, E., C. (1993) Fingerprint recognition in low quality images. Pattern Recognition, Vol. 26, pp 1441-1460.

He, Y., Zheng, Y., Zhao, Y., Ren, Y., Lian, J., Gee, J. (2017). Retinal Image Denoising via Bilateral Filter with a Spatial Kernel of Optimally Oriented Line Spread Function. Comput Math Methods Med.

Hetmanczyk, M. and Michalski, P. (2013) The Aid of a Mistake Proofing with the use of Mechatronic Systems According to the Poka-Yoke Methodology, Advanced Materials Research, 2014 Vol. 837, pp. 399-404

IFM electronic $\mathrm{GmbH}$ O3D301 software manual (2017). https://www.ifm.com/mounting/706395UK.pdf [Accessed 05 June 2019].

IFM electronic $\mathrm{GmbH}$ O3D301 operating instructions (2018). https://www.ifm.com/mounting/706397UK.pdf [Accessed 05 June 2019].

IFM electronic $\mathrm{GmbH}$ O3D301 software manual (2018). https://www.ifm.com/mounting/7391233UK.pdf [Accessed 05 June 2019].

Ivanov, D., Tabachinikov, S. (2019). The Six Circles Theorem revisited. https://www.math.psu.edu/tabachni/prints/Circles.pdf [Accessed 06 June 2019].

Lankton, S., Tannenbaum, A. (2008). Localizing Region-Based Active Contours. IEEE Trans Image Process. Nov: 17(11), 2029-2039.

Michalski, P. (2016). Czujniki przemysłowe XXI wieku, kierunki rozwoju a oczekiwania klientów, [online] Volume 1/2016, p. 42-44. Available at: https://emtsystems.pl/images/czujniki_przemyslowe_xxi_wieku.pdf [Accessed 01 June 2019].

Michalski, P. (2018). Collecting data from industrial sensors in case of 4-th industrial revolution. IOP Conf. Ser.: Mater. Sci. Eng. 2018, vol. 400

Michalski, P. and Hetmanczyk, M. (2015). Implementation of the safety components base on industrial networks. IOP Conf. Ser.: Mater. Sci. Eng. 2015, vol. 95

Michalski, P. (2019). Advantages of Using Industrial Sensor Interfaces at the Machine Design Stage. In: Świder J., Kciuk S., Trojnacki M., ed., Mechatronics 2017 - Ideas for Industrial Applications. MECHATRONICS 2017. Advances in Intelligent Systems and Computing, vol 934. Springer, pp. 308-313

Nalepa, B., Gwiazda, A., Banas, W. (2018) Investigation of movement of mobile robot work. IOP Conference Series: Materials Science and Engineering, Vol. 400.

OpenCV documentation (2019). https://docs.opencv.org/ref/2.4.13/ [Accessed 06 June 2019].

PMDSKD2 documentation (2019).

https://support.bluetechnix.at/wiki/PMDSDK_/_PMDMDK_User_Manual [Accessed 06 June 2019].

SICK AG UM30 documentation (2018). https://cdn.sick.com/media/docs/6/06/206/Operating_instructions_UM30_21_111

_UM30_21_115_de_en_IM0032206.PDF [Accessed 03 June 2019].

SICK $\quad A \bar{G}-\overline{P I M 60}$ quick https://cdn.sick.com/media/docs/5/35/835/quickstart_Inspector_PIM60_de_en_fr_ zh_it_es_IM0048835.PDF [Accessed 04 June 2019].

SICK AG PIM60 operating instruction (2018). https://cdn.sick.com/media/docs/6/36/836/Operating_instructions_Inspector_PIM 60_ver_2.0_en_IM0048836.PDF [Accessed 04 June 2019].

SICK $\quad \overline{A G}$ PIM60 reference manual (2018). https://cdn.sick.com/media/docs/6/16/316/User_manual_Inspector_PIM60_ver_2. 0_en_IM0081316.PDF [Accessed 04 June 2019]. 
Stevenhagen, P. (2019). Pumber $\quad$ Rings. http://websites.math.leidenuniv.nl/algebra/ant.pdf [Accessed 06 June 2019].

Tan, T., He, Z., Sun, Z. (2010) Efficient and robust segmentation of noisy iris images for non-cooperative iris recognition. Image and Vision Computing, Vol. 28, pp 223230.

Yoruk, E., Konukoglu, E., Sankur, B., Darbon, J. (2006) Shape-based hand recognition. Transactions on Image Processing, Vol. 15, pp 1803-1815.

\begin{abstract}
.
The purpose of the paper is to present the validity of the investment of a production plant in the development of production automation. The optimal use of production lines is the way to achieve the right return on investment and profits. Any unplanned stops reduce profitability of production and do not allow to achieve high production output. The introduction of various types of safety devices and process automation allows to prevent unwanted events. In particular, relieving employees of their responsibility and thus avoiding breakdowns caused by operator error can lead to an effective increase in Overall Equipment Effectiveness (OEE). The publication presents a study of the impact of the use of a vision system on increasing the reliability of the production system. As a result, an effective vision system based on a 3D sensor has been developed, which protects the production line against collision of the robot's chuck plate with final products, thus not leading to the collision and destruction of the robot's tools. The camera has been implemented in the robot's control system, which excludes the need to change the settings, because the necessary change of work parameters is made automatically via the communication interface, thus making the work easier for employees when retooling the production machine between orders. Increasing the Overall Equipment Effectiveness and high level of Return Of Investment (ROI) allow for an unequivocal decision on the importance of the investment decision. The financial expense allowed for increasing the efficiency and productivity of production line, which contributes to the growth of the company's competitiveness. The predictability of lead time has been significantly improved, which led to an increase in customer satisfaction.
\end{abstract}

Keywords: vision, production, OEE, automation, reliability 